\title{
Timoshenko Beam based Coupled Torsion Beam Axle Modeling Method
}

\author{
Minsoo Hyun $^{1}$ Deaoh Kang ${ }^{1}$ Seung-jin $\mathrm{Heo}^{2}$ Jingyu Moon ${ }^{2}$ \\ ${ }^{1}$ Graduate School of Automotive Engineering, Kookmin University, Korea, s lay@ kookmin . ac.kr \\ ${ }^{1}$ Institute of vehicle Engineering, Korea, bigfive@ivh.co.kr \\ ${ }^{2}$ School of Automotive Engineering, Kookmin University, Korea, s jheo@kookmin.ac. kr \\ ${ }^{2}$ Institute of vehicle Engineering, Korea, j kmoon@ivh. co. kr
}

\begin{abstract}
This paper investigates the coupled torsion beam axle (CTBA) modeling method based on Timoshenko beam theory. Timoshenko beam elements are applied to torsion beams that cause large deformations, and rigid bodies are applied to parts such as spring mounts, trailing arms and knuckles. Timoshenko beam modeling was modeled using the modelica language, and the remaining components and test rigs were modeled using Modelon's Vehicle dynamics library (VDL). To evaluate the accuracy of the model constructed in this way, the opposite wheel travel simulation is performed and the results are compared with the CTBA model based on the full flexible body. As a result of the test, the error of the roll stiffness and the trailing arm axial force are all within $3 \%$.
\end{abstract}

Keywords: Timoshenko Beam Theory, Coupled Torsion Beam Axle(CTBA), Roll Stiffness

\section{Introduction}

Coupled torsion beam axle (CTBA) is a suspension in which the centrally located torsion beam for the opposite wheel travel generates roll torque. Generally used for rear suspension of small vehicles. This CTBA is mainly applied to the flexible body model because of the torsion beam causing large deformation. However, the flexible body model is inefficient when designing hardpoints and torsion beam properties because the model can be modeled only after the shape is defined.

This paper proposes a Timoshenko beam-based CTBA dynamic model with hardpoints and torsion beam properties as modeling parameters. In Section 2, we introduce the $6 \mathrm{DOF}$ (degree of freedom) Timoshenko beam modeling method based on Modelica language and propose CTBA dynamic modeling method using it. Section 3 describes the opposite wheel travel simulation, an example of the Timoshenko beam based CTBA model, and Section 4 evaluates the accuracy by comparing the simulation results with those of Adams / car's flexible body CTBA model.

\section{Timoshenko Beam based CTBA Model}

\subsection{Timoshenko Beam Model}

The 6 DOF Timoshenko beam model used in the dynamics model is shown in Eq. (1).

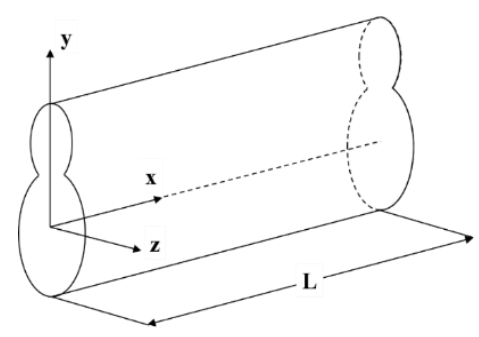

Figure 1. Coordinate System of Beam Model

$$
\left[\begin{array}{c}
F_{x} \\
F_{y} \\
F_{z} \\
T_{x} \\
T_{y} \\
T_{z}
\end{array}\right]=-\left[\begin{array}{cccccc}
\frac{E A}{L} & 0 & 0 & 0 & 0 & 0 \\
0 & \frac{12 E I_{z z}}{L^{3}\left(1+P_{y}\right)} & 0 & 0 & 0 & \frac{-6 E I_{z z}}{L^{2}\left(1+P_{y}\right)} \\
0 & 0 & \frac{12 E I_{y y}}{L^{3}\left(1+P_{z}\right)} & 0 & \frac{6 E I_{y y}}{L^{2}\left(1+P_{z}\right)} & 0 \\
0 & 0 & 0 & \frac{G I_{x x}}{L} & 0 & 0 \\
0 & 0 & \frac{6 E I_{y y}}{L^{2}\left(1+P_{z}\right)} & 0 & \frac{4 E I_{y y}}{L\left(1+P_{z}\right)} & 0 \\
0 & \frac{-6 E I_{z z}}{L^{2}\left(1+P_{y}\right)} & 0 & 0 & 0 & \frac{4 E I_{z z}}{L}\left(1+P_{y}\right)
\end{array}\right]\left[\begin{array}{c}
d x-L \\
d y \\
d z \\
\theta_{x} \\
\theta_{y} \\
\theta_{z}
\end{array}\right]-C\left[\begin{array}{c}
V_{x} \\
V_{y} \\
V_{z} \\
\omega_{x} \\
\omega_{y} \\
\omega_{z}
\end{array}\right] \quad(1)
$$

$P_{y}$ and $P_{z}$ are factors for considering shear deformation. This equation was compared with the results of EulerBernouli beam, finish element model by creating a model using Modelica language and bending simulations.

Table 1. Bending test results of beam models

\begin{tabular}{|c|c|c|c|c|}
\hline $\begin{array}{c}\text { Input } \\
\text { force } \\
{[\mathrm{N}]}\end{array}$ & $\begin{array}{c}\text { Beam } \\
\text { length } \\
{[\mathrm{mm}]}\end{array}$ & $\begin{array}{c}\text { Euler- } \\
\text { Bernoulli }\end{array}$ & Timoshenko & FEM \\
\hline \multirow{3}{*}{1200} & 500 & 0.3575 & 0.3710 & 0.3710 \\
\cline { 2 - 5 } & 1000 & 2.8599 & 2.8869 & 2.8869 \\
\cline { 2 - 5 } & 1500 & 9.6521 & 9.6926 & 9.6926 \\
\hline
\end{tabular}

As a result of comparison, as the beam length gets shorter, the Euler-Bernoulli beam has little error with the Timoshenko beam, which has a larger error with the finite element model. This shows that Timoshenko beams are more suitable for beams with small aspect ratios. 


\subsection{Torsion Beam Modeling}

The torsion beam used in CTBA is divided into constant region with constant cross section and transition region with gradually changing cross section as shown in Figure 2. To realize this, in this paper, the constant region consists of one beam element and the transition region represents the change of the cross section by applying five beam elements to each of the left and right sides. Since the transition region is short, a Timoshenko beam of Section 2.1 is suitable because a beam element with a small aspect ratio is used.

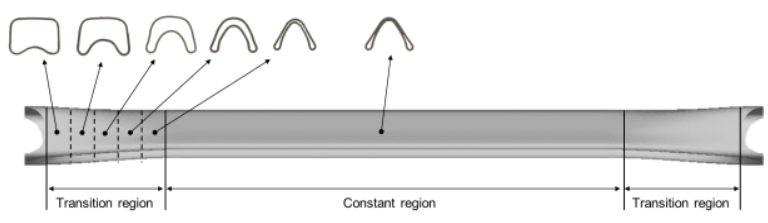

Figure 2. Regions of Torsion Beam

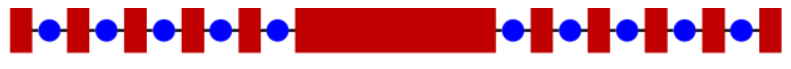

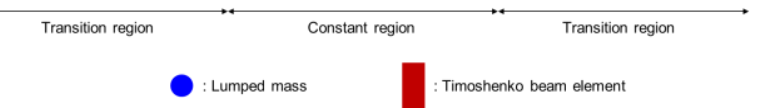

Figure 3. Timoshenko Beam based Torsion Beam Model

The torsion beam model in Figure 3 is implemented in Modelica language as shown in Figure 4. The red model is the Timoshenko beam element and the blue model is the lumped mass.

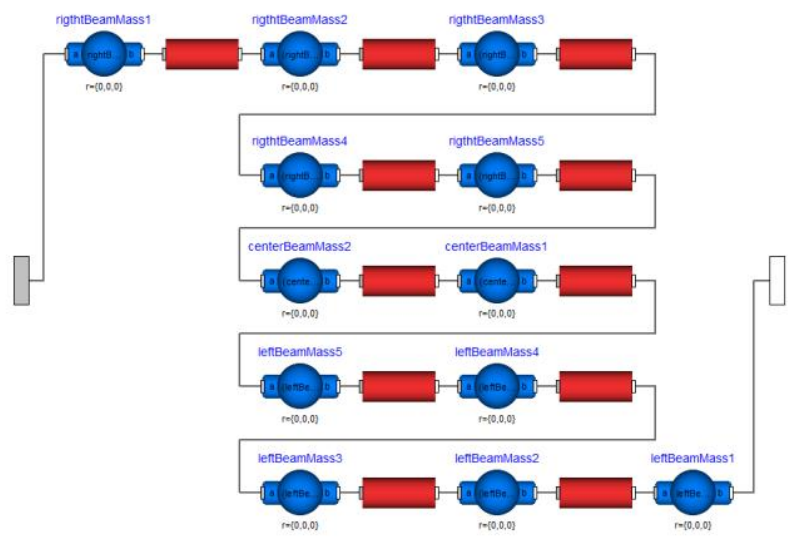

Figure 4. Modelica based Torsion Beam Model

To compare the developed torsion beam model with the FE (finite element) torsion beam model, static bending test and static torsion test were conducted. The bending test and torsion test were conducted by fixing one side of the torsion beam as shown in Figure 3 and applying a force of $200 \mathrm{~N}$ downward and $200 \mathrm{Nm}$ torque in the axial direction, respectively. As shown in Table 4 , all test results showed the accuracy within $5 \%$.

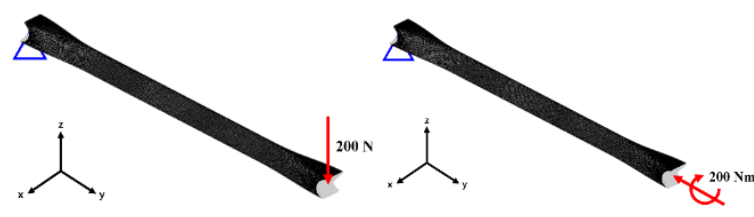

a) Static Bending Test

Figure 5. Static Test

b) Static Torsion Test

Table 2. Torsion test results of beam models

\begin{tabular}{|c|c|c|c|c|}
\hline Test & $\begin{array}{c}\text { Output } \\
\text { variable }\end{array}$ & $\begin{array}{c}\text { Timoshenko } \\
\text { torsion } \\
\text { beam model }\end{array}$ & $\begin{array}{c}\text { FE } \\
\text { torsion } \\
\text { beam } \\
\text { model }\end{array}$ & Error \\
\hline $\begin{array}{c}\text { Bending } \\
\text { Test }\end{array}$ & $\begin{array}{c}\text { Displacement } \\
{[\mathrm{mm}]}\end{array}$ & 1.2024 & 1.2486 & $3.7 \%$ \\
\hline $\begin{array}{c}\text { Torsion } \\
\text { Test }\end{array}$ & Angle $\left[^{\circ}\right]$ & 2.2551 & 2.3592 & $4.4 \%$ \\
\hline
\end{tabular}

\subsection{CTBA Modeling}

The torsion beam model constructed in Section 2.1 is combined with the remaining parts to form the CTBA model. First, the components of the trailing arm, knuckle, spring lower mount, etc. are configured as a rigid body model so that the hardpoints of the CTBA can be directly changed. Force elements such as springs, dampers, bushes, and bump stoppers form the model based on the parameters in Table 3 . Figure 4 shows the major components of the CTBA model. Modeling was done using Modelon's Vehicle Dynamics Library (VDL).

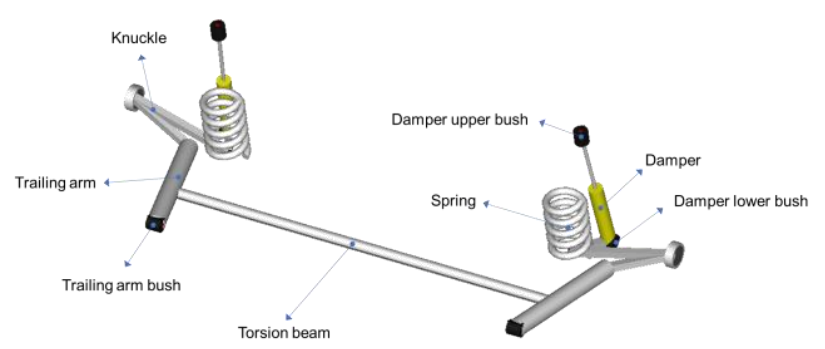

Figure 6. Components of CTBA Model

Table 3. Parameters of CTBA Model

\begin{tabular}{|c|c|c|}
\hline Category & Parameters & Units \\
\hline \multirow{7}{*}{ Hardpoints } & Wheel center & \multirow{7}{*}{$\mathrm{mm}$} \\
\hline & Trailing arm mount & \\
\hline & Damper upper mount & \\
\hline & Damper lower mount & \\
\hline & Spring upper mount & \\
\hline & Spring lower mount & \\
\hline & Torsion beam mount & \\
\hline \multirow{2}{*}{ Spring } & Stiffness & $\mathrm{N} / \mathrm{mm}$ \\
\hline & Preload & $\mathrm{N}$ \\
\hline Damper & Force-Velocity table & \multirow{2}{*}{ 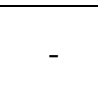 } \\
\hline Bump stopper & Force-Displacement table & \\
\hline
\end{tabular}




\begin{tabular}{|c|c|}
\hline \multirow{2}{*}{ Bush } & 6 DOF stiffness table \\
\hline & 6 DOF damping coefficient \\
\hline
\end{tabular}

\section{CTBA Multibody Dynamic Simulation}

In this paper, the opposite wheel travel simulation is performed to verify the accuracy of the proposed Timoshenko beam CTBA model and to proceed with the application case. The opposite wheel travel is a test that generates roll torque by inputting vertical displacement in the opposite direction to the left and right wheels. The test rig is constructed by connecting an actuator that can input vertical displacement to the wheel center of the CTBA model, as shown in Figure 5. The input profile used in this paper is shown in Figure 6.

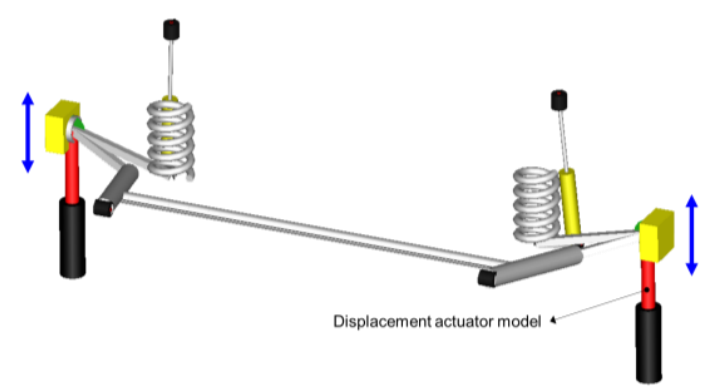

Figure 7. Opposite Wheel Travel Test Rig

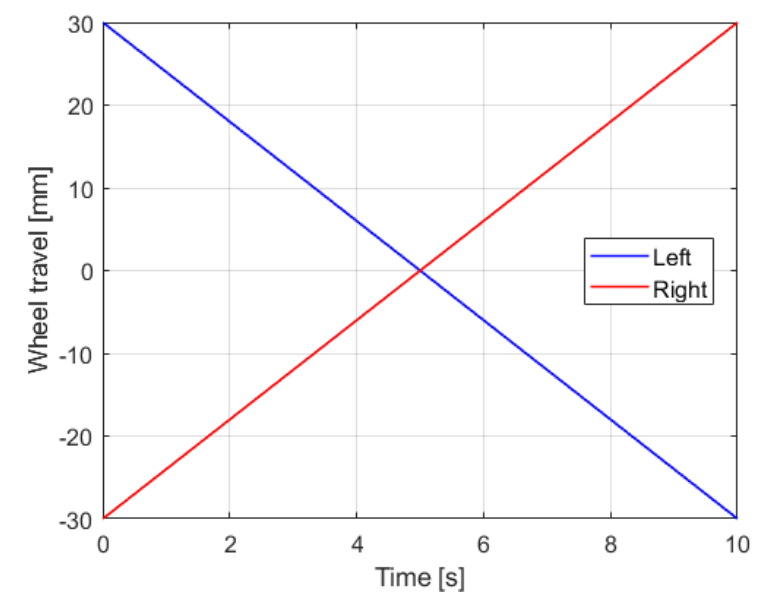

Figure 8. Input Signal of Opposite Wheel Travel

\section{Validation Result}

In the opposite wheel travel simulation, the roll torque of the suspension is compared with the axial force of the trailing arm. Figure 7 shows the output curves of the two models for roll angle. Table 4 shows the error of roll stiffness value, peak to peak value of trailing arm axial force of the two models.
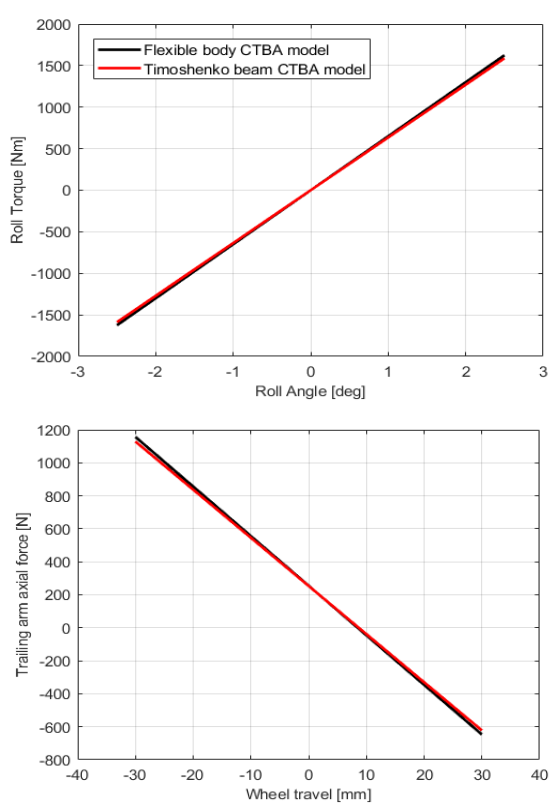

Figure 9. Opposite Wheel Travel Simulation Results (top: roll torque, bottom: trailing arm axial force)

Table 4. Opposite Wheel Travel Simulation Results

\begin{tabular}{|c|c|c|c|}
\hline & $\begin{array}{c}\text { Timoshenko } \\
\text { beam } \\
\text { CTBA }\end{array}$ & $\begin{array}{c}\text { Flexible } \\
\text { body } \\
\text { CTBA }\end{array}$ & Error \\
\hline $\begin{array}{c}\text { Roll stiffness } \\
\text { [Nm/deg] }\end{array}$ & 635.07 & 650.18 & $2.32 \%$ \\
\hline $\begin{array}{c}\text { Peak to Peak } \\
\text { value of } \\
\text { trailing arm axial } \\
\text { force [N] }\end{array}$ & 1751.94 & 1804.28 & $2.90 \%$ \\
\hline
\end{tabular}

The root mean square(RMS) error between the output values of both models was within $3 \%$. This demonstrates that the accuracy of the Timoshenko beam CTBA model proposed in this study is close to that of the flexible body CTBA model.

\section{Conclusion}

In this paper, we developed a Timoshenko beam based CTBA model that can calculate the dynamic response of CTBA according to hardpoints and torsion beam properties. The model was created using the Modelica language and Modelon's Vehicle Dynamics Library (VDL).

Modeling method is as follows.

- The torsion beam section of the CTBA consists of Timoshenko beam elements. The rest of the parts, such as the trailing arm and the knuckle, were applied with the rigid body. In this way, the model is configured to have hardpoints and torsion beam properties as variables. 
- A total of 11 Timoshenko beam elements were used to implement the transition region of the torsion beam section.

To evaluate the accuracy of the constructed Timoshenko beam CTBA model, opposite wheel travel simulation was performed. The model compared is the flexible body CTBA model. The root mean square error between the output values of the two models was high within $3 \%$. In this paper, the opposite wheel travel simulation is a quasi-static test, and the verification of the dynamic test has not been performed. In the future, we will also verify dynamic tests such as virtual testing labs(VTL) and full vehicle based R\&H(Ride and Handling) simulation.

\section{References}

Vehicle Dynamics Library, Modelon, 2019.

Chen,J., Jiang, Y. Qin, M. et al. (2015). CAD/CAE and Optimization of a Twist Beam Suspension System. SAE Technical Paper Series.

Chen,J., Jiang, M. Jiang, Y. et al. (2015). Modeling, analysis and optimization of the twist beam suspension system. $S A E$ International Journal of Commercial Vehicles 8(2015-010623):38-44.

Choi, B., Choi, D., Min, J. et al. (2009) Torsion beam axle system design with a multidisciplinary approach. International Journal of Automotive Technology 10(1):49 54.

CFichera, G., L:acagnina, M., Petrone, F. (2004) Modelling of torsion beam rear suspension by using multibody method. Multibody system dynamics 12(4):303-316. 